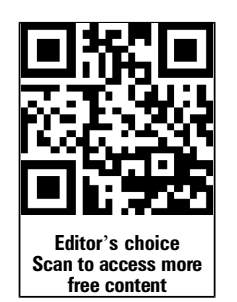

For numbered affiliations see end of article.

\section{Correspondence to} Dr Alexandra L Quittner, Department of Psychology \& Pediatrics, University of Miami, 5665 Ponce de Leon Blvd Coral Gables, FL 33146, USA; aquittner@miami.edu

Received 2 July 2014 Revised 26 August 2014 Accepted 28 August 2014 Published Online First 22 September 2014

\section{SLinked}

- http://dx.doi.org/10.1136/ thoraxjnl-2014-206200

\section{CrossMark}

To cite: Quittner $A L$ Goldbeck L, Abbott J, et al. Thorax 2014;69:

1090-1097.

\title{
Prevalence of depression and anxiety in patients with cystic fibrosis and parent caregivers: results of The International Depression Epidemiological Study across nine countries
}

\author{
Alexandra L Quittner, ${ }^{1}$ Lutz Goldbeck, ${ }^{2}$ Janice Abbott, ${ }^{3}$ Alistair Duff, ${ }^{4}$ \\ Patrick Lambrecht, ${ }^{5}$ Amparo Solé, ${ }^{6}$ Marijke M Tibosch, ${ }^{7}$ Agneta Bergsten Brucefors, ${ }^{8}$ \\ Hasan Yüksel, ${ }^{9}$ Paola Catastini, ${ }^{10}$ Laura Blackwell, ${ }^{11}$ Dave Barker ${ }^{12}$
}

ABSTRACT

Background Individuals with chronic diseases and parent caregivers are at increased risk for symptoms of depression and anxiety. Prevalence of psychological symptoms was evaluated in adolescents and adults with cystic fibrosis (CF) and parent caregivers across nine countries.

Methods Patients with CF, ages 12 years and older, and caregivers of children with CF, birth to 18 years of age, completed measures of depression and anxiety across 154 CF centres in Europe and the USA. Psychological symptoms were compared across countries using $\chi^{2}$. Logistic regression examined extent of comorbid symptoms, predictors of depression and anxiety, and concordance between parent and adolescent symptomatology.

Results Psychological symptoms were reported by 6088 patients with CF and 4102 parents. Elevated symptoms of depression were found in $10 \%$ of adolescents, $19 \%$ of adults, $37 \%$ of mothers and $31 \%$ of fathers. Elevations in anxiety were found in $22 \%$ of adolescents, $32 \%$ of adults, $48 \%$ of mothers and $36 \%$ of fathers. Overall, elevations were 2-3 times those of community samples. Participants reporting elevated anxiety were more likely to report depression (ORs: adolescents $=14.97$, adults $=13.64$, mothers $=15.52$, fathers $=9.20$ ). Significant differences in reports of depression and anxiety were found by patient age and parent respondent. Concordance between 1122 parentteen dyads indicated that adolescents whose parents reported depression were more likely to be elevated on depression $(\mathrm{OR}=2.32)$. Similarly, adolescents whose parents reported anxiety were more likely to score in the elevated range on the anxiety measure $(\mathrm{OR}=2.22)$.

Conclusions Symptoms of depression and anxiety were elevated in both patients with CF and parents across several European countries and the USA. Annual screening of psychological symptoms is recommended for both patients and parents.

\section{INTRODUCTION}

Meta-analyses and systematic reviews have indicated that children and adults with chronic diseases, as well as parent caregivers, are at increased risk for depression and anxiety. ${ }^{1-3}$ Cystic fibrosis

\section{Key messages}

What is the key question?

- What is the prevalence of symptoms of depression and anxiety in adolescents and adults with cystic fibrosis (CF) and parents of children with $\mathrm{CF}$, ages from birth to 17 years, in an international study across 9 countries using standardised screening measures?

\section{What is the bottom line?}

- Significant elevations in symptoms of depression and anxiety were found among patients and parent caregivers across countries, suggesting that screening for symptoms of depression and anxiety should be performed annually and addressed systematically.

\section{Why read on?}

- This is the largest international screening study performed in a chronic respiratory disease and has led to the creation of an international guidelines committee to formulate recommendations leading to a change in medical practice.

(CF) is the most common genetic, life-limiting chronic disease among Caucasian populations and requires a treatment regimen that takes between 2 and $4 \mathrm{~h}$ per day. ${ }^{4}$ Patients have genetic mutations that affect the CF transmembrane conductance regulator protein, leading to thick mucus secretions, repeated infections and progressive failure of most organ systems (e.g., lungs, pancreas, digestive, reproductive). ${ }^{5}$ Although recent advances in diagnosis and treatment have led to increases in lifespan, CF continues to be one of the most difficult chronic conditions to manage. ${ }^{6}$

Studies evaluating depression and anxiety in patients with $\mathrm{CF}$ have generally found a high prevalence of psychological distress. Rates of depression in children and adolescents have ranged from $9 \%$ to $29 \%$, using different methods of assessment (ICD-10 diagnoses, Children's 
Depression Inventory). ${ }^{7}$ For adults with $\mathrm{CF}$, rates of depression have ranged from $13 \%$ to $30 \%{ }^{8}$ and rates of anxiety from $30 \%$ to $33 \% .^{8}{ }^{10}$ Among parent caregivers, elevations in psychological distress have also been found, with depression ranging from $20 \%$ to $35 \% .^{7} 1112$ Overall, psychological symptoms appear to be higher in this population than community samples ${ }^{13}$; however, these studies have been limited by small sample sizes and different screening or diagnostic tools, which have made interpretation of the results difficult. Additionally, the majority of studies have only assessed symptoms of depression but not anxiety.

Psychological distress in patients with CF has been associated with a number of negative consequences and health outcomes, including worse adherence, ${ }^{7}{ }^{14}$ worse pulmonary function, ${ }^{10} 15$ increased hospitalisations and healthcare costs, ${ }^{16}$ and decreased health-related quality of life. ${ }^{8} 9$ A recent study ${ }^{16}$ compared adolescents with CF who had been diagnosed with a depressive disorder with a matched sample of non-depressed teens with $\mathrm{CF}$, and found that those who were depressed were three times more likely to be hospitalised for a pulmonary exacerbation, and incurred much higher healthcare costs over 2 years (US $\$ 280000$ for the depressed group vs. US\$60116 for the nondepressed group). Given both the wide range of prevalence estimates for patients with CF and their caregivers, and the negative impact these symptoms have on disease management and functioning, The International Depression Epidemiological Study group aimed to screen depression and anxiety in several European countries and the USA. Two screening measures were used to assess these symptoms in both adolescents and adults with CF and parent caregivers. Predictors of psychological symptoms, both demographic and medical, were also identified, comorbidity of depression and anxiety was estimated and concordance between parents and children was evaluated.

\section{METHODS}

\section{Procedure}

This study was conducted at $154 \mathrm{CF}$ centres in nine countries: Belgium, Germany, Italy, Spain, Sweden, The Netherlands, Turkey, the UK and the USA. The protocol was developed by a consortium of investigators over a 2-year period, with discussions each year in Europe and the USA to refine the protocol. Investigators then applied for funding from their country's respective patient with CF or research foundations, with 7 out of 9 countries obtaining small grants. Although the procedures and data collection were standardised to a great extent, some countries chose to use only one screening tool for depression (i.e., Hospital Anxiety and Depression Scale; HADS) because it was widely used in their country ${ }^{17}$ (note that the HADS is not used in the USA). Five out of the nine countries used both the HADS and the Center for Epidemiologic Studies-Depression Scale (CES-D). Screening was initiated in patients aged 12 years through adulthood and in parents of children from birth to 18 years of age. Study protocols were approved by national and local ethics committees or institutional review boards at all CF centres.

Staff members approached participants at routine, stable, clinic visits. After completion of consent/assent, patients or parents completed a basic demographic questionnaire in addition to the screening measures. When both parents were present, they completed the symptom measures independently. Depression and anxiety screening measures were scored immediately by trained staff members to identify clinically elevated scores; referrals were provided if necessary. Completion of the measures took approximately $15 \mathrm{~min}$. Medical data were collected through chart review.

\section{Participants}

Across nine countries, 1286 adolescents (mean age $=14.84$ years, $\mathrm{SD}=1.69$ ) and 4739 adults (mean age $=28.87$ years, $\mathrm{SD}=9.5$ ) with $\mathrm{CF}$ were screened. Inclusion criteria were: (1) confirmed diagnosis of CF, (2) age within specified range and (3) screening during stable clinic visit. Patients who had received a solid organ transplant were excluded. Additionally, 3127 mothers and 975 fathers of younger children reported on their own symptoms. Descriptive demographic and medical data are presented in table 1 .

\section{Measures}

Demographic and medical characteristics

Parents and young adults completed a Background Information Form assessing parent and child/adolescent's age, gender and education. Information about pharmacological and psychological treatment of depression and anxiety was also collected. Indicators of physical health status in the past 6 months were recorded from medical charts $\left(\mathrm{FEV}_{1} \%\right.$ predicted, height, weight, haemoptysis/pneumothorax, intravenous antibiotics, and listed for transplant).

\section{Hospital Anxiety and Depression Scale}

The HADS is a 14-item instrument; seven questions measure depression and seven measure anxiety. ${ }^{18}$ It has extensive reliability and validity data, and was designed specifically for patients with chronic medical conditions (i.e., removal of somatic items). Respondents indicated the severity of each symptom on a 4-point rating scale (0-3) over the past week. Maximum score is 21; participants were categorised using established cut-off scores $($ mild $=8-10$, moderate $=11-15$, severe $=\geq 16)$. Validated translations were used in Europe.

\section{Center for Epidemiologic Studies-Depression scale}

The CES-D is a well-established self-report measure of depressive symptomatology for community samples. ${ }^{19}$ It has 20 items measuring symptoms of depression that reflect diagnostic criteria on the DSM-IV and has correlated well with diagnostic interviews. Items are rated on a 4-point scale from 0 to 3, with higher scores indicating more depressive symptoms. The maximum score is 60 , with $\geq 16=$ elevated. Valid translations were used in Europe.

\section{Statistical analyses}

\section{Missing data}

Missing data occurred because some countries did not collect data on both screening measures or because participants did not provide a response. Countries that did not collect information on a particular measure were excluded from the analyses that involved that measure or question. The amount of missing data from participants who did not provide a response ranged from $0 \%$ to $7 \%$, depending on the measure. Because few participant responses were missing, this was unlikely to significantly bias the results, and we opted to use complete cases in all analyses. ${ }^{20}$

\section{Nesting of participants within country}

Participants were nested within 9 countries. In analyses that pooled data across countries, this nesting was accounted for by including country as a fixed effect (i.e., different intercept for each country) in the models. We chose to use a fixed effect approach because we did not have specific hypotheses about 
Table 1 Participant characteristics by respondent

\begin{tabular}{|c|c|c|c|c|c|c|c|c|}
\hline & \multicolumn{8}{|l|}{ Respondent } \\
\hline & Adolescent & Adult & OR or $\eta^{2}$ & p Value & Mothers* & Fathers* & OR or $\eta^{2}$ & $p$ Value \\
\hline Sample size & 1286 & 4739 & & & 3127 & 975 & & \\
\hline Age, mean (SD), years & $14.84(1.69)$ & $28.87(9.54)$ & 0.32 & $<0.001$ & $8.90(5.08)$ & $8.52(5.14)$ & $<0.01$ & 0.040 \\
\hline Female (\%) & $669(53)$ & $2271(48)$ & 1.14 & 0.044 & $1558(50)$ & $460(47)$ & 1.14 & 0.075 \\
\hline BMI, mean (SD) & $19.54(3.11)$ & $21.87(3.54)$ & 0.07 & $<0.001$ & $17.47(2.99)$ & $17.28(2.92)$ & $<0.01$ & 0.102 \\
\hline $\mathrm{FEV}_{1}$ percent predicted, mean (SD) & $83.78(23.44)$ & $62.32(24.51)$ & 0.12 & $<0.01$ & $89.23(21.55)$ & $90.74(22.13)$ & $<0.01$ & 0.112 \\
\hline $\begin{array}{l}\text { Haemoptysis or pneumothorax in } \\
6 \text { months }(\%)\end{array}$ & $35(3)$ & $657(14)$ & 0.21 & $<0.001$ & $37(1)$ & $9(1)$ & 0.98 & 0.969 \\
\hline Currently on intravenous antibiotics (\%) & $156(12)$ & $733(16)$ & 0.50 & $<0.001$ & $299(10)$ & $118(12)$ & 1.22 & 0.146 \\
\hline Listed for transplant (\%) & $7(1)$ & $243(5)$ & 0.09 & $<0.001$ & $12(0.4)$ & $1(0.1)$ & - & - \\
\hline $\begin{array}{l}\text { Currently on psychiatric medication for } \\
\text { depression/anxiety (\%) }\end{array}$ & 44 (4) & $466(10)$ & 0.29 & $<0.001$ & $59(2)$ & $9(0.9)$ & 1.95 & 0.231 \\
\hline $\begin{array}{l}\text { Currently receiving psychotherapy for } \\
\text { depression/anxiety (\%) }\end{array}$ & $70(6)$ & $379(8)$ & 0.63 & 0.001 & $103(3)$ & $19(2)$ & 1.23 & 0.526 \\
\hline Positive scores (\%) & & & & & Caregivers & & & \\
\hline HADS-D & $60(5)$ & $609(13)$ & 0.30 & $<0.001$ & $618(20)$ & $173(18)$ & 1.15 & 0.142 \\
\hline CES-D & $87(19)$ & $488(29)$ & 0.53 & $<0.001$ & $1057(34)$ & $240(25)$ & 1.58 & $<0.001$ \\
\hline Either HADS-D or CES-D & $130(10)$ & 913 (19) & 0.39 & $<0.001$ & $1165(37)$ & $305(31)$ & 1.34 & $<0.001$ \\
\hline HADS-A & $281(22)$ & 1503 (32) & 0.60 & $<0.001$ & $1496(48)$ & $343(36)$ & 1.70 & $<0.001$ \\
\hline
\end{tabular}

*Characteristics of younger patients whose parents completed the screening. The amount of variability across strata was estimated using $\eta^{2}$ for continuous variables. ORs comparing younger with older participants and Mothers with Fathers, were used to index the size of the differences between the strata.

HADS, Hospital Anxiety and Depression Scale; CES-D, Center for Epidemiologic Studies-Depression Scale; BMI, body mass index.

difference between countries, did not want to make assumptions about countries not included in the sample and because the limited number of countries posed challenges for alternative approaches (e.g., multilevel modelling). ${ }^{21}$

\section{Demographic and prevalence estimates}

Prevalence estimates were based on published cut scores, ${ }^{18} 19$ and then divided into two groups according to 'caseness': (1) non-case (below cut-off) and (2) case (mild-severe symptoms). Demographic and prevalence estimates were analysed using two stratifications. Estimates were first stratified by a respondent to test differences by respondent age ( $<18$ vs. $\geq 18$ years) and by mothers vs. fathers. Differences between ages and respondents on dichotomous variables were tested using a Generalised Linear Model (GLIM) with a binomial error distribution and a logit link function. The size of the difference between strata was quantified using ORs comparing younger with older respondents, and mothers with fathers. Similar GLIMs were used for all analyses of dichotomous outcomes that pooled data across countries. Differences on continuous variables were estimated using a General Linear Model, and $\eta^{2}$ was used to quantify the size of the differences. Estimates were also stratified by country to test for variability among countries. For dichotomous variables, variability across strata was tested using a $\chi^{2}$ test, and the amount of variability was estimated using Cramér's $V\left(\varphi_{c}\right)$. For continuous items, the variability was tested using a General Linear Model, and $\eta^{2}$ was used to quantify the amount of variability.

\section{Comorbidity and concordance}

Theoretically, a great deal of evidence suggests that anxiety often precedes depression, ${ }^{22}$ therefore, a GLIM was used to assess the odds of reporting elevations in depression given respondents' reports of anxiety. Concordance between 1130 parent-adolescent dyads was also evaluated using a GLIM. The model evaluated the odds that adolescents would report symptoms above the cut-off given that their parents also reported symptoms above the cut-off; these analyses were conducted separately for depression and anxiety scores.

\section{Predictors of depression and anxiety}

To identify predictors of depression and anxiety, data were pooled across countries and stratified by participant age ( $<18$ vs. $\geq 18$ years) and respondent (mother vs. father). Potential predictors included the 9 variables collected on the Demographic and Medical Characteristics form and are listed in tables 1 and 2. Each predictor was evaluated separately using a GLIM that accounted for country of origin.

All analyses were run using SAS V.9.3.

\section{RESULTS}

\section{Demographics}

Demographic and health information for patients and caregivers are presented in table 1 and are reported by country in table 2 . On average, patients were in their mid-20s, about half were female, body mass index (BMI) was in the normal range and lung function indicated moderate disease severity. Significant variability was found across countries on age, gender, BMI and $\mathrm{FEV}_{1} \%$ predicted, however, these effects were small. Across countries, variability was also found in the predictors of psychological distress: haemoptysis/pneumothorax (2\%-32\%), currently on intravenous antibiotics (5\%-19\%), listed for transplant $(2 \%-12 \%)$, and pharmacological/psychological treatment of depression or anxiety $(3 \%-23 \%)$.

\section{Prevalence of symptoms of depression}

Rates of depression varied depending on age and screening tool: adolescents 5\%-19\%, adults 13\%-29\%, mothers $20 \%-$ $34 \%$ and fathers $18 \%-25 \%$ (table 1 and figure 1). Analyses by country indicated that overall, $11 \%$ of patients were elevated on the HADS-D (range $8 \%-15 \%$ ) and $27 \%$ of patients were elevated on the CES-D (range 20\%-31\%) (table 2). Because the 
Table 2 Participant characteristics by country

\begin{tabular}{|c|c|c|c|c|c|c|c|c|c|c|c|c|}
\hline & \multicolumn{12}{|l|}{ Countries } \\
\hline & $\mathrm{BE}$ & DE & IT & NL & ES & SE & TR & UK & US & TOTAL & $\begin{array}{l}\varphi_{c} \text { or } \\
\eta^{2}\end{array}$ & $\begin{array}{l}\mathrm{p} \\
\text { Value }\end{array}$ \\
\hline Sample size & 426 & 663 & 741 & 515 & 275 & 167 & 52 & 2042 & 1207 & 6088 & & \\
\hline Age, mean (SD), years & $\begin{array}{l}25.55 \\
(10.09)\end{array}$ & $23.53(9.22)$ & $24.52(9.38)$ & $\begin{array}{l}27.50 \\
(11.39)\end{array}$ & $25.82(7.81)$ & $\begin{array}{l}26.84 \\
(12.16)\end{array}$ & $12.86(5.97)$ & $\begin{array}{l}26.98 \\
(10.18)\end{array}$ & $\begin{array}{l}25.40 \\
(10.86)\end{array}$ & $\begin{array}{l}25.76 \\
(10.31)\end{array}$ & 0.03 & $<0.001$ \\
\hline Female & $201(47)$ & $316(48)$ & $383(52)$ & $239(47)$ & $119(43)$ & $81(49)$ & $32(63)$ & $993(49)$ & $527(53)$ & $2963(49)$ & 0.06 & 0.014 \\
\hline BMI, mean (SD) & $20.58(3.34)$ & $19.93(2.98)$ & $20.52(3.05)$ & $21.33(3.15)$ & $21.36(3.82)$ & $21.84(3.33)$ & $18.71(3.99)$ & $22.10(3.78)$ & $21.70(3.83)$ & $21.34(3.60)$ & 0.05 & $<0.001$ \\
\hline $\mathrm{FEV}_{1}$ percent predicted, mean (SD) & $\begin{array}{l}72.34 \\
(24.55)\end{array}$ & $\begin{array}{l}67.22 \\
(25.60)\end{array}$ & $\begin{array}{l}73.83 \\
(26.97)\end{array}$ & $\begin{array}{l}66.25 \\
(26.12)\end{array}$ & $\begin{array}{l}64.67 \\
(26.12)\end{array}$ & $\begin{array}{l}74.66 \\
(26.89)\end{array}$ & $\begin{array}{l}71.90 \\
(26.26)\end{array}$ & $\begin{array}{l}62.55 \\
(24.49)\end{array}$ & $\begin{array}{l}67.89 \\
(26.08)\end{array}$ & $\begin{array}{l}66.99 \\
(25.84)\end{array}$ & 0.03 & $<0.001$ \\
\hline Haemoptysis/pneumothorax last 6 months & $31(7)$ & $27(4)$ & - & $101(24)$ & $32(12)$ & $4(4)$ & $1(2)$ & $279(14)$ & $223(32)$ & $698(14)$ & 0.17 & $<0.001$ \\
\hline Currently on intravenous antibiotics & $72(17)$ & - & - & 56 (11) & $14(5)$ & $19(19)$ & $8(18)$ & $129(6)$ & $182(17)$ & $461(11)$ & 0.16 & $<0.001$ \\
\hline Received an organ transplant & $10(2)$ & $18(3)$ & - & 27 (6) & 20 (7) & $2(2)$ & $1(2)$ & $43(2)$ & $131(12)$ & $252(5)$ & 0.18 & $<0.001$ \\
\hline $\begin{array}{l}\text { Currently on psychiatric medication for depression/ } \\
\text { anxiety }\end{array}$ & $40(9)$ & $14(2)$ & - & $16(3)$ & 17 (6) & $8(5)$ & $3(7)$ & $158(8)$ & $257(23)$ & $513(10)$ & 0.24 & $<0.001$ \\
\hline $\begin{array}{l}\text { Currently receiving psychotherapy for depression/ } \\
\text { anxiety }\end{array}$ & $22(5)$ & $53(9)$ & - & $17(3)$ & $13(5)$ & $11(12)$ & $3(7)$ & $145(7)$ & $190(18)$ & $401(9)$ & 0.17 & $<0.001$ \\
\hline HADS depression & & & & & & & & & & & 0.08 & $<0.001$ \\
\hline Non-case (0-7) & $361(85)$ & $599(90)$ & $683(86)$ & $466(90)$ & $244(89)$ & $154(92)$ & $37(71)$ & $1810(89)$ & $1052(91)$ & $5361(89)$ & & \\
\hline Case (8-21) & $65(15)$ & $63(10)$ & $103(14)$ & $49(10)$ & $31(11)$ & $13(8)$ & $15(29)$ & $232(11)$ & $100(9)$ & $671(11)$ & & \\
\hline CES-D depression & $106(28)$ & - & - & $102(20)$ & 75 (31) & - & $16(52)$ & - & $259(29)$ & $558(27)$ & 0.11 & $<0.001$ \\
\hline Either HADS or CES-D & $122(29)$ & $63(10)$ & $103(14)$ & $114(22)$ & $83(30)$ & $13(8)$ & $30(58)$ & $232(11)$ & $287(25)$ & 1047 (17) & 0.11 & $<0.001$ \\
\hline HADS Anxiety & & & & & & & & & & & 0.14 & $<0.001$ \\
\hline Non-case $(0-7)$ & $286(67)$ & $526(79)$ & $486(66)$ & $443(86)$ & $204(74)$ & $129(77)$ & $36(69)$ & $1374(67)$ & $755(66)$ & $4239(70)$ & & \\
\hline Case (8-21) & $140(33)$ & $136(21)$ & $255(34)$ & $72(14)$ & $71(26)$ & $38(23)$ & $16(31)$ & 668 (34) & 397 (35) & $1793(30)$ & & \\
\hline
\end{tabular}

Notes: unless otherwise noted, values represent No. (\%), only participants with non-missing values were included in the calculation of the percentages.

Shading shows data from Turkey which were not used in the logistic regression. The amount of variability across strata was estimated using Cramér's $V\left(\varphi_{0}\right)$ for categorical variables and $\eta^{2}$ for continuous variables.

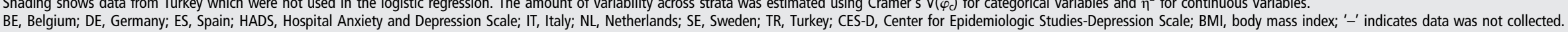


Patient Rates of Depression

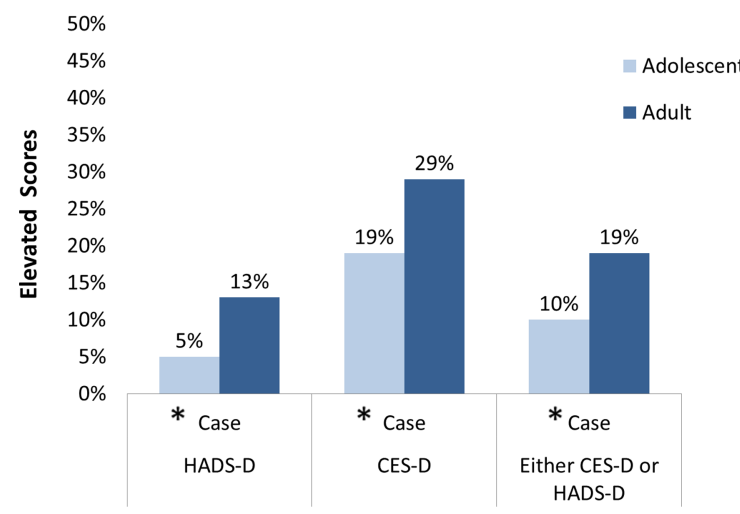

Caregiver Rates of Depression

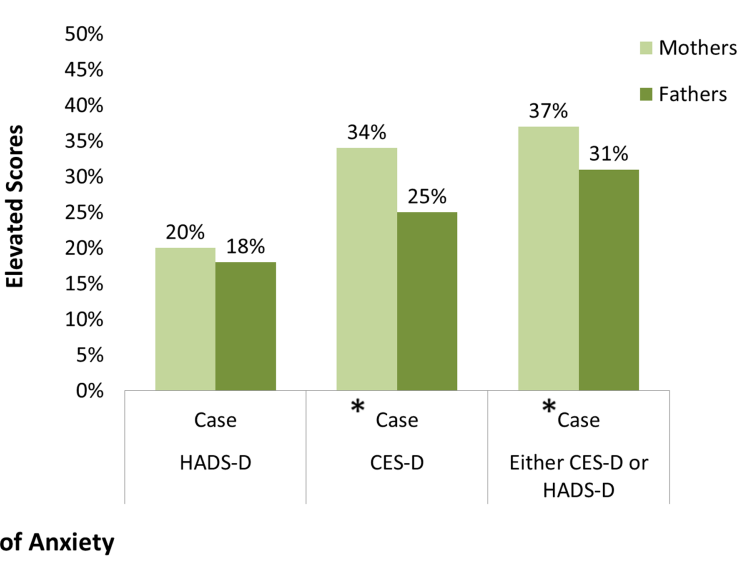

Figure 1 Rates of depression and anxiety by respondent.

sample size for Turkey was small and the availability of standard medications for CF is limited, their estimates were not included in the ranges above (i.e., Turkey: depression on the HADS-D $=29 \%$, CES-D $=52 \%)$. Statistically significant differences were found by age (see table 1), with adolescents reporting fewer symptoms of depression than adults $(19 \%$ vs. $29 \%$ on the CES-D; $\mathrm{p}<0.001)$. Mothers reported significantly more depressive symptoms than fathers on the CES-D (34\% vs. $25 \%$; $\mathrm{p}<0.001)$, but not on the HADS-D ( $20 \%$ vs. $18 \%)$.

For the countries that administered both the CES-D and HADS-D to patients, significant differences in prevalence rates were found between measures. Comparing the CES-D with the HADS-D, the OR for adolescents was $4.45(\mathrm{p}<0.001)$ and the OR for adults was $2.90(\mathrm{p}<0.001)$. For mothers, the OR was $1.88(\mathrm{p}<0.001)$ and for fathers it was $1.09(\mathrm{p}=0.650)$.

\section{Prevalence of symptoms of anxiety}

Symptoms of anxiety were prevalent in patients and parents: adolescents $22 \%$, adults $32 \%$, mothers $48 \%$ and fathers $36 \%$ (see table 1 and figure 1). Analyses by country indicated high rates of anxiety among patients (mean 30\%), with moderate variability across countries (14\%-35\%; Turkey falls within this range). Statistically significant differences were found by age, with $22 \%$ of adolescents vs. $32 \%$ of adults $(p<0.001)$ reporting elevations in anxiety above the cut-off score (see table 1 , figure 1). Mothers also reported significantly more symptoms of anxiety than fathers ( $48 \%$ vs. $36 \%, \mathrm{p}<0.001)$.

\section{Comorbidity between depression and anxiety}

In terms of both the theory ${ }^{22}$ and the higher rates of anxiety observed across both patients and parents, bidirectional relationships between anxiety and depression were examined by calculating the odds that those with elevated anxiety would also score in the elevated range for depression. Adolescents reporting elevated anxiety had odds of reporting depression that were 14.97 times higher than adolescents not reporting anxiety; 6\% of adolescents reported elevations on both. Adults reporting anxiety were 13.64 times more likely to report elevated depression than those not elevated on anxiety; $14 \%$ of adults reported elevations on both. Mothers reporting elevated anxiety were 15.52 times more likely to report elevations in depression; $31 \%$ reported elevations on both. For fathers with elevated anxiety, they were 9.20 times more likely to report elevated depression; $21 \%$ reported elevations on both. All effect sizes were large.

\section{Concordance between parent and adolescent depression and anxiety}

For the 1122 dyads with both parent and teen reports, adolescents were 2.39 times more likely be above the cut-off for depression if at least one of their parents had elevated symptoms and they were 2.22 times more likely to be above the cut-off for anxiety if their parent was also elevated.

\section{Predictors of depression and anxiety}

Predictors of depression and anxiety were identified using univariate logistic regressions (see table 3). For adolescents, the following characteristics were associated with elevated symptoms of depression on the CES-D or HADS-D: being female, an episode of haemoptysis/pneumothorax in past 6 months, taking psychiatric medication for depression or anxiety and receiving psychotherapy for depression or anxiety. Characteristics associated with elevated anxiety were: being female, recently on IV antibiotics and receiving psychotherapy. 
Table 3 Univariate logistic regression results predicting depression or anxiety by respondent

\begin{tabular}{|c|c|c|c|c|c|c|c|c|}
\hline & \multicolumn{8}{|l|}{ Respondent } \\
\hline & \multicolumn{2}{|l|}{ Adolescent } & \multicolumn{2}{|l|}{ Adult } & \multicolumn{2}{|l|}{ Mother } & \multicolumn{2}{|l|}{ Father } \\
\hline & $\begin{array}{l}\text { Odds ratio }(95 \% \\
\mathrm{Cl})\end{array}$ & $\begin{array}{l}p \\
\text { Value }\end{array}$ & $\begin{array}{l}\text { Odds ratio }(95 \% \\
\mathrm{Cl})\end{array}$ & $\begin{array}{l}p \\
\text { Value }\end{array}$ & $\begin{array}{l}\text { Odds ratio }(95 \% \\
\mathrm{Cl})\end{array}$ & $\begin{array}{l}p \\
\text { Value }\end{array}$ & $\begin{array}{l}\text { Odds ratio }(95 \% \\
\mathrm{Cl})\end{array}$ & $\begin{array}{l}p \\
\text { Value }\end{array}$ \\
\hline \multicolumn{9}{|l|}{ HADS or CESD depression } \\
\hline Age, years & 1.01 (0.89 to 1.13$)$ & 0.963 & 1.03 (1.02 to 1.04$)$ & $<0.001$ & $0.99(0.98$ to 1.01$)$ & 0.315 & $0.99(0.96$ to 1.01$)$ & 0.304 \\
\hline Female & 1.77 (1.17 to 2.66$)$ & 0.007 & $1.09(0.94$ to 1.26$)$ & 0.277 & 0.95 (0.81 to 1.10$)$ & 0.472 & $0.93(0.70$ to 1.23$)$ & 0.610 \\
\hline BMI & $1.03(0.98$ to 1.10$)$ & 0.261 & $1.01(0.99$ to 1.03$)$ & 0.266 & 1.01 (0.98 to 1.03$)$ & 0.696 & $1.03(0.99$ to 1.09$)$ & 0.173 \\
\hline $\mathrm{FEV}_{1}$ percent predicted ${ }^{*}$ & $0.98(0.90$ to 1.06$)$ & 0.621 & $0.90(0.88$ to 0.93$)$ & $<0.001$ & 1.00 (0.96 to 1.04$)$ & 0.971 & 0.95 (0.88 to 1.03$)$ & 0.198 \\
\hline $\begin{array}{l}\text { Haemoptysis/pneumothorax in last } \\
6 \text { months }\end{array}$ & 3.82 (1.63 to 8.95$)$ & 0.002 & 1.62 (1.33 to 1.98$)$ & $<0.001$ & $0.96(0.47$ to 1.97$)$ & 0.920 & $1.29(0.31$ to 5.34$)$ & 0.723 \\
\hline Intravenous antibiotics & 1.74 (0.94 to 3.21$)$ & 0.076 & 1.65 (1.33 to 2.04$)$ & $<0.001$ & 1.53 (1.17 to 2.01$)$ & 0.002 & $1.72(1.12$ to 2.63$)$ & 0.013 \\
\hline Received an organ transplant $\dagger$ & - & - & 1.39 (1.03 to 1.87$)$ & 0.030 & $1.10(0.31$ to 3.85$)$ & 0.880 & - & - \\
\hline $\begin{array}{l}\text { Currently on psychiatric medication } \\
\text { for depression/anxiety }\end{array}$ & 3.96 (1.94 to 8.08$)$ & 0.003 & 3.56 (2.86 to 4.42$)$ & $<0.001$ & 1.51 (0.88 to 2.61$)$ & 0.137 & $0.68(0.14$ to 3.33$)$ & 0.631 \\
\hline $\begin{array}{l}\text { Currently receiving psychotherapy for } \\
\text { depression/anxiety }\end{array}$ & 6.54 (3.56 to 12.01) & $<0.001$ & 3.21 (2.54 to 4.06$)$ & $<0.001$ & 1.88 (1.25 to 2.83$)$ & 0.002 & 0.52 (0.15 to 1.84$)$ & 0.313 \\
\hline \multicolumn{9}{|l|}{ HADS anxiety } \\
\hline Age, years & 0.99 (0.91 to 1.07$)$ & 0.790 & 1.02 (1.01 to 1.03$)$ & $<0.001$ & $0.98(0.97$ to 1.00$)$ & 0.034 & $0.98(0.95$ to 1.00$)$ & 0.082 \\
\hline Female & 1.63 (1.23 to 2.15$)$ & $<0.001$ & 1.66 (1.46 to 1.88$)$ & $<0.001$ & 0.94 (0.81 to 1.09$)$ & 0.404 & 0.83 (0.63 to 1.09$)$ & 0.173 \\
\hline BMI & 0.99 (0.95 to 1.04$)$ & 0.793 & 1.03 (1.01 to 1.05$)$ & 0.003 & 0.99 (0.97 to 1.02$)$ & 0.504 & 0.98 (0.94 to 1.03$)$ & 0.530 \\
\hline $\mathrm{FEV}_{1}$ percent predicted ${ }^{*}$ & $1.01(0.95$ to 1.07$)$ & 0.765 & $0.96(0.93$ to 0.98$)$ & 0.002 & 0.99 (0.95 to 1.03$)$ & 0.541 & 0.99 (0.91 to 1.06$)$ & 0.706 \\
\hline $\begin{array}{l}\text { Haemoptysis/pneumothorax in last } \\
6 \text { months }\end{array}$ & 2.03 (0.99 to 4.14$)$ & 0.053 & $1.38(1.15$ to 1.65$)$ & $<0.001$ & 1.32 (0.67 to 2.58$)$ & 0.424 & 0.82 (0.20 to 3.44 ) & 0.790 \\
\hline Intravenous antibiotics & 1.73 (1.13 to 2.66$)$ & 0.012 & 1.14 (0.94 to 1.37$)$ & 0.185 & 1.52 (1.16 to 1.98$)$ & 0.002 & $1.10(0.71$ to 1.71$)$ & 0.674 \\
\hline Received an organ transplant $\dagger$ & - & - & 1.34 (1.01 to 1.77$)$ & 0.039 & 0.91 (0.29 to 2.90$)$ & 0.879 & - & - \\
\hline $\begin{array}{l}\text { Currently on psychiatric medication } \\
\text { for depression/anxiety }\end{array}$ & 1.91 (1.00 to 3.68$)$ & 0.051 & 3.37 (2.74 to 4.14$)$ & $<0.001$ & 0.97 (0.57 to 1.65$)$ & 0.919 & 0.64 (0.16 to 2.63$)$ & 0.537 \\
\hline $\begin{array}{l}\text { Currently receiving psychotherapy for } \\
\text { depression/anxiety }\end{array}$ & 2.77 (1.65 to 4.62$)$ & $<0.001$ & 4.22 (3.37 to 5.30$)$ & $<0.001$ & 2.02 (1.32 to 3.09 ) & $<0.001$ & 2.03 (0.79 to 5.17$)$ & 0.139 \\
\hline
\end{tabular}

${ }^{*}$ ORs are for a $10 \%$ change in $\mathrm{FEV}_{1}$ percent predicted.

†Variable was not included in the model for 12-year-olds to 18-year-olds due to small number of cases.

HADS, Hospital Anxiety and Depression Scale; CES-D, Center for Epidemiologic Studies-Depression Scale; BMI, body mass index.

For adults, depression was associated with: older age, lower $\mathrm{FEV}_{1} \%$ predicted, haemoptysis or pneumothorax in the past 6 months, recently on intravenous antibiotics, listed for transplant, taking psychiatric medications and receiving psychotherapy. Characteristics associated with elevated symptoms of anxiety were: older age, being female, lower BMI, lower $\mathrm{FEV}_{1}$, haemoptysis/pneumothorax, listed for transplant, taking psychiatric medications and receiving psychotherapy.

For mothers, child characteristics associated with depression were: recently on intravenous antibiotics and receiving psychotherapy. Elevated anxiety was associated with: younger age, recent intravenous antibiotics and receiving psychotherapy. For fathers, only one child medical variable was associated with depression: recent intravenous antibiotics.

\section{DISCUSSION}

This is the largest psychological screening study conducted in a chronic respiratory disease, with data collected from both European countries and the USA. Results across nine countries revealed high rates of depression and anxiety in adolescents and adults with $\mathrm{CF}$, as well as parent caregivers. Elevated depression was reported by $17 \%$ of patients across countries, regardless of which screening tool was used-a rate two times that reported in community populations $(9.2 \%){ }^{23}$ Similarly, although there are fewer large-scale studies of caregivers, $37 \%$ of mothers and $31 \%$ of fathers reported clinically elevated depression, which is three times the rate in community samples. ${ }^{23}{ }^{24}$ Rates of anxiety were also elevated in patients and caregivers, with $30 \%$ of patients and $36 \%-48 \%$ of parents above the clinical cut-off. These rates are two to three times those reported in community samples. ${ }^{25-27}$

Given these high rates of psychological symptoms and their documented effects on disease management, including clinic attendance and adherence to prescribed treatments, ${ }^{7} 1628$ annual screening of depression and anxiety for adolescents and adults with CF and parent caregivers is warranted. This conclusion is consistent with several international guidelines, which recommend regular screening for adolescents and adults with chronic conditions-particularly if these symptoms impact daily functioning and management of the disease. ${ }^{29-32}$ For example, the American Diabetes Association recommends screening of psychological symptoms at 'regular clinical encounters' and when there is 'concern about poor management'. ${ }^{32}$ To date, however, there is no guideline recommendation for screening parent caregivers.

As found in prior studies, comorbidity of anxious and depressive symptoms within individuals was high, suggesting that elevations in anxiety confer a heightened risk for depression. Analyses of parent-adolescent dyads showed that depression or anxiety in either parent doubled the risk that the adolescent would report elevated psychological distress. This wellestablished comorbidity between parents and adolescents provides a second rationale for screening parent caregivers. Identification and treatment of parental psychological distress 
may both prevent adolescents with CF from developing psychological symptoms, and when detected in parents, prompt the medical team to provide referrals for mental health services to the family.

We used two well-established screening measures of depression, and in countries that used both (i.e., 5 out of 9 countries), comparisons indicated that the HADS-D underestimated symptoms of depression by a factor of two. Although when the study protocol was being developed, the HADS was considered well established and widely used, more recent evidence has clearly shown that this screening tool has significant problems, including lack of sensitivity, underestimation of symptoms and a threefactor, rather than two-factor structure, and is not recommended for screening. ${ }^{33-35}$ Additionally, it was chosen because it did not contain somatic items (e.g., fatigue). A posthoc analysis of the rank ordering of depressive symptoms on the CES-D in our patient sample, showed that no somatic items were ranked among the top three. In fact, the symptoms with the highest severity ratings focused on hopefulness about the future, selfesteem and extent of happiness. Further, a comparison of items on the HADS-D and CES-D revealed that many of the diagnostic criteria in the DSM-IV/V were not represented on the HADS-D (e.g., cognitive impairment, lack of energy). Instead, the vast majority of items on the HADS-D measured anhedonia (72\%), which represents lack of enjoyment and pleasure in activities. ${ }^{36}$ By contrast, the CES-D included items representing the full spectrum of depressive symptoms underlying this construct.

Several risk factors were associated with elevated depression and anxiety. Older age and female sex, worse disease severity, as indicated by lower lung function or BMI, and recent changes in health status (past 6 months), such as haemoptysis or prescription of intravenous antibiotics. Treatments for psychological distress (with medication or psychotherapy) were the highest risk factors. For parents, recent course of intravenous antibiotics and current treatment for a psychological disorder were associated with greater symptomatology.

\section{Limitations and future directions}

Although the demographic and health information from the three largest samples in this study (UK, USA and Germany) appeared quite similar to data in their respective national registries, ${ }^{11} 15$ it is possible that this sample is not representative of the larger international population. In screening studies, those who are experiencing the most severe symptoms are less likely to attend regular clinic visits or give informed consent for participation in research, and thus, these prevalence rates may be an underestimate of the population. ${ }^{37}$ This study was also limited by the cross-sectional nature of the data collection. Prospective, longitudinal studies are needed to determine: which health variables predict increases in psychological symptoms and what health consequences follow identification of elevated scores (e.g., decreased adherence, increases in pulmonary exacerbations, increases in healthcare use and cost, decreases in health-related quality of life).

These results highlight the importance of measuring and treating mental health issues in patients and families coping with serious, chronic illnesses. Our findings, in conjunction with other smaller studies, have led to the formation of an international committee, sponsored by both the European Cystic Fibrosis Society and the Cystic Fibrosis Foundation, to develop guidelines on mental health screening and treatment in CF. As advocated by other national guidelines committees, we have recommended annual screening of depression and anxiety in adolescents and adults with CF, and parent caregivers using the
PHQ-9 and GAD-7. ${ }^{23}$ 30-32 3839 Our goals are to implement these screening recommendations using the unique structure of accredited and recognised CF centres in Europe and the USA and to take advantage of the existing data registries in Europe, the UK and the USA to better understand the relationships between psychological distress and health outcomes.

\section{Author affiliations}

${ }^{1}$ Department of Psychology \& Pediatrics, University of Miami, Coral Gables, Florida, USA

${ }^{2}$ Department of Child and Adolescent Psychiatry/Psychotherapy, University Hospital Ulm, Ulm, Germany

${ }^{3}$ School of Psychology, University of Central Lancashire, Preston, UK

${ }^{4}$ The Regional Paediatric CF Unit, Leeds Teaching Hospitals NHS Trust, Leeds, Yorkshire, UK

${ }^{5}$ Department of Clinical and Lifespan Psychology, Free University Brussels, Brussels, Belgium

${ }^{6}$ Adult CF and Lung Transplant Unit, University Hospital la Fe, Valencia, Spain ${ }^{7}$ Department of Medical Psychology, Radboud University Nijmegen Medical Centre, Nijmegen, The Netherlands

${ }^{8}$ Stockholm CF Centre, Karolinska University Hospital Huddinge, Karolinska institute, Stockholm, Sweden

${ }^{9}$ Medical Faculty, Department of Pediatric Allergy and Pulmonology, Celal Bayar University, Manisa, Turkey

${ }^{10}$ Meyer Hospital CF Regional Centre, Florence, Pediatric Department, Italy

${ }^{11}$ Department of Psychiatry, Children's Hospital Boston, Boston, Massachusetts, USA

${ }^{12}$ Department of Psychiatry and Human Behavior, Brown University, Providence,

Rhode Island, USA

Acknowledgements The authors would like to thank all the study centres and all patients and parent caregivers who contributed to this study. We would also like to thank Alexandra Monzon and Estefany Saez-Flores for their assistance with the literature review and editing of the manuscript. We would like to acknowledge the effort that Tanja Besier contributed to coordinating the German part of the study. We thank Christianne Verhaak and Peter Merkus who were the grant holders and PIs in The Netherlands. We appreciate the efforts of Monica Cebrian in coordinating study in Spain. We would like to thank Ozge Yilmaz for her contribution to data collection in Turkey. We thank Carolyn Cowperthwaite, Clare Sumner and Margaret Hurley for their sizeable contribution to collecting and collating the UK data. We would like to thank Karleen De Rijcke, Danielle Huse and the psychologists working in the Belgian CF centres for their data collection. We thank Roberto Buzzetti for his assistance with data entry in Italy.

Collaborators Tanja Besier; Christianne Verhaak; Peter Merkus; Monica Cebrian; Ozge Yilmaz; Carolyn Cowperthwaite; Clare Sumner; Margaret Hurley; Karleen De Rijcke; Danielle Huse; Roberto Buzzetti; Alexandra Monzon; Estefany Saez-Flores.

Contributors ALQ was lead author, grant holder, and manager of the database, data collection, data analysis and interpretation, and writing of the article. LG participated in planning the study, was responsible PI and grant holder of the German part of the study, and participated in data interpretation and writing of the article. JA and AD participated in planning the study, was responsible PI and grant holder of the UK part of the study, and participated in data interpretation and writing of the article. PL was responsible for obtaining the funding in Belgium, overseeing the data collection and entry, assisting with analysis of the data and interpretation of the results, and writing the manuscript. AS was responsible for the coordination and data collection of the Spanish part of the study and participated in the interpretation and writing of the article. MT was responsible for the coordination and data collection of the Dutch part of the study and participated in the interpretation and writing of the article. $A B$ was responsible for collecting and entering the data for Sweden, interpreting the results, and writing the manuscript. $\mathrm{HY}$ was responsible for collecting and entering the data for Turkey, interpreting the results and writing the manuscript. PC was responsible for collecting and entering the data, interpreting the results of the Italian part of the study, and writing the manuscript. LB was responsible for creating the database, cleaning the data, assisting with data analyses and interpretation and writing the manuscript. DB was responsible for planning the study, developing the database, cleaning the data, assisting with the analyses and interpretation, and writing the manuscript.

Funding Cystic Fibrosis Foundation; Mukoviszidose Institut gGmbH, Dutch Cystic Fibrosis Organization (NCFS), Spanish Cystic Fibrosis Federation (FEFQ), CF Italian Foundation grant, UK CF Trust, The Belgian CF Association.

Competing interests None.

Ethics approval Ethics and Institutional Review Boards of all 9 countries and CF centres.

Provenance and peer review Not commissioned; externally peer reviewed. 
Data sharing statement The corresponding author confirms she had full access to all the data in the study and had final responsibility for the decision to submit for publication.

\section{REFERENCES}

1 Pinquart M, Shen Y. Depressive symptoms in children and adolescents with chronic physical illness: an updated meta-analysis. J Pediatr Psychol 2011;36:375-84.

2 Fauman KR, Pituch KJ, Han YY, et al. Predictors of depressive symptoms in parents of chronically ill children admitted to the pediatric intensive care unit. Am J Hosp Palliat Care 2011;28:556-63.

3 Moussavi S, Chatterji S, Verdes E, et al. Depression, chronic diseases, and decrements in health: results from the World Health Surveys. Lancet 2007;370:851-8

4 Sawicki GS, Rasouliyan LR, McMullen AH, et al. Longitudinal assessment of health-related quality of life in an observational cohort of patients with cystic fibrosis. Pediatr Pulmonol 2011;46:36-44.

5 Lobo LJ, Peadar G, Noone PG. Respiratory infections in patients with cystic fibrosis undergoing lung transplantation. Lancet Respir Med 2014;2:73-82.

6 Quittner AL, Alpern AN, Blackwell LS. Treatment adherence in adolescents with cystic fibrosis. In: Castellani C, Elborn S, Heijerman $\mathrm{H}$, eds. Health care issues and challenges in the adolescent with cystic fibrosis. Oxford, UK: Elsevier Inc., 2012:77-9.

7 Smith BA, Modi AC, Quittner AL, et al. Depressive symptoms in children with cystic fibrosis and parents and its effects on adherence to airway clearance. Pediatr Pulmonol 2010;45:756-63.

8 Havermans T, Colpaert K, Dupont LJ. Quality of life in patients with Cystic Fibrosis: association with anxiety and depression. J Cyst Fibros 2008;7:581-4.

9 Riekert KA, Bartlett SJ, Boyle MP, et al. The association between depression, lung function, and health-related quality of life among adults with cystic fibrosis. Chest 2007;132:231-7.

10 Yohannes AM, Willgoss TG, Fatoye FA, et al. Relationship between anxiety, depression, and quality of life in adult patients with cystic fibrosis. Respir Care 2012:57:550-6.

11 Latchford G, Duff AJ. Screening for depression in a single CF centre. J Cyst Fibros 2013;12:794-6.

12 Besier T, Born A, Henrich G, et al. Anxiety, depression, and life satisfaction in parents caring for children with cystic fibrosis. Pediatr Pulmonol, 2011;46:672-82.

13 Costello EJ, Erkanli A, Angold A. Is there an epidemic of child or adolescent depression? J Child Psychol Psychiatry 2006:47:1263-71.

14 Grenard JL, Munjas BA, Adams JL, et al. Depression and medication adherence in the treatment of chronic diseases in the United States: a meta-analysis. J Gen Intern Med 2011:26:1175-82.

15 Goldbeck L, Besier T, Hinz A, et al. Prevalence of symptoms of anxiety and depression in German patients with cystic fibrosis. Chest 2010;138:929-36.

16 Snell C, Fernandes S, Bujoreanu IS, et al. Depression, illness severity, and healthcare utilization in cystic fibrosis. Pediatr Pulmonol. Published Online First: 12 Mar 2014. doi:10.1002/ppul.22990

17 Herrmann C. International experiences with the Hospital Anxiety and Depression Scale-a review of validation data and clinical results. J Psychosom Res 1997:42:17-41.

18 Zigmond AS, Snaith RP. The hospital anxiety and depression scale. Acta Psychiatric Scand 1983:67:361-70.
19 Radloff LS. The use of the Center for Epidemiologic Studies Depression Scale in adolescents and young adults. J Youth Adolesc 1991;20:149-66.

20 Widaman KF. Missing data: what to do with or without them. Monogr Soc Res Child Dev 2006:71:42-64.

21 Senn S. Some controversies in planning and analyzing multi-centre trials. Stat Med 1998;17:1753-65.

22 Brady EU, Kendall PC. Comorbidity of anxiety and depression in children and adolescents. Psychol Bull 1992:111:244-55.

23 Martin A, Rief W, Klaiberg A, et al. Validity of the brief patient health questionnaire mood scale (PHQ-9) in the general population. Gen Hosp Psychiatry 2006;28:71-7.

24 Pignone MP, Gaynes BN, Rushton JL, et al. Screening for depression in adults: a summary of the evidence for the US Preventive Services Task Force. Ann Intern Med 2002:136:765-76

25 Dierker LC, Albano AM, Clarke GN, et al. Screening for anxiety and depression in early adolescence. J Am Acad Child Adolesc Psychiatry 2001:40:929-36.

26 Eisenberg D, Gollust SE, Golberstein E, et al. Prevalence and correlates of depression, anxiety, and suicidality among university students. Am J Orthopsychiatry 2007;77:534-42

27 Davis B, Sheeber $L$, Hops $H$, et al. Adolescent responses to depressive parental behaviors in problem-solving interactions: Implications for depressive symptoms. J Abnorm Child Psychol 2000;28:451-65.

28 Quittner AL, Zhang J, Marynchenko $\mathrm{M}$, et al. Pulmonary medication adherence and healthcare utilization in cystic fibrosis. Chest 2014;146:142-51.

29 National Institute for Clinical Excellence (Great Britain). Depression in children and young people: identification and management in primary, community and secondary care. Leicester, UK: British Psychological Society, 2005.

30 Simon GR, Baker C, Barden GA III, et al. 2014 recommendations for pediatric preventative health care. Pediatrics 2014:133:568-70.

31 Cheung AH, Zuckerbrot RA, Jensen PS, et al. Guidelines for Adolescent Depression in Primary Care (GLAD-PC): II. Treatment and ongoing management. Pediatrics 2007;120:e1313-26.

32 American Diabetes Association. Standards of medical care in diabetes-2013. Diabetes Care 2013;36(Suppl 1):S11-66.

33 Martin CR. What does the Hospital Anxiety and Depression Scale (HADS) really measure in liaison psychiatry settings? Curr Psychiatry Rev 2005;1:69-73.

34 Cameron IM, Crawford JR, Lawton K, et al. Psychometric comparison of PHQ-9 and HADS for measuring depression severity in primary care. Br J Gen Pract 2008;58:32-6.

35 Cameron IM, Cardy A, Crawford JR, et al. Measuring depression severity in general practice: discriminatory performance of the PHQ-9, HADS-D, and BDI-II. Br J Gen Pract 2011;61:e419-26.

36 American Psychiatric Association. Diagnostic and statistical manual of mental disorders. 5th edn. Arlington, VA: American Psychiatric Publishing, 2013.

37 Cohen BJ, McGarvey EL, Pinkerton RC, et al. Willingness and competence of depressed and schizophrenic inpatients to consent to research. J Am Acad Psychiatry Law 2004;32:134-43.

38 US Preventive Services Task Force. Screening and treatment for major depressive disorder in children and adolescents: US Preventive Services Task Force Recommendation Statement. Pediatrics 2009;123:1223-8.

39 Gilbody S, Richards D, Brealey $S$, et al. Screening for depression in medical settings with the Patient Health Questionnaire (PHQ): a diagnostic meta-analysis. J Gen Intern Med 2007:22:1596-602. 